\title{
Fausto, nosso contemporâneo
}

Klaus F. W. Eggensperger ${ }^{2}$

CC NCOMENSURÁVEL" é a avaliação que a Segunda Parte do Fausto recebeu várias vezes de seu próprio criador, por exemplo, numa conversa com Eckermann em fevereiro de 1831, quando o poeta octogenário diz que no seu Fausto "o todo permanece incomensurável, mas, justamente por isso, como um problema não solucionado, continuará estimulando as pessoas a sempre retomar seu estudo" (Eckermann, 2016, p.428). Quanto maior a complexidade de um texto canônico, tanto maior o dilema do crítico literário: ao fazer uma releitura atualizadora, sua tarefa paradoxal consiste em despertar o interesse do público sem reduzir a complexidade estética, filosófica e social da obra em questão.

$\mathrm{Na}$ sua renomada edição brasileira comentada do Fausto, Marcus Mazzari enfrentou "o problema não solucionado", deixando o drama goethiano mais comensurável para os leitores de língua portuguesa do século XXI. Agora, com a monografia $A$ dupla noite das tilias, Mazzari (2019) nos oferece de certa forma um comentário mais extenso ainda, desta vez focalizado no quinto e último ato da tragédia. Conversando com a história cultural do Ocidente como um todo, com os clássicos Dante, Shakespeare, Marx, Schopenhauer, entre muitos outros, com os viajantes europeus no Brasil do século XIX e com a bicentenária história da recepção da obra, o autor não se contenta em trazer resultados da pesquisa europeia para o nosso contexto. Como pesquisador brasileiro que é, está também em constante diálogo com a literatura nacional, com os romances
Quincas Borba ou Grande sertão, por exemplo.

Um belo exemplo disso é a discussão das primeira e segunda cenas do último ato do Fausto II. Em Goethe, Filemon e Baucis, casal conhecido das Metamorfoses de Ovídio, vivem pacificamente em uma paisagem onde natureza e cultura estão interligadas de forma harmoniosa - ou melhor: estavam interligadas, pois os arredores da região já foram transformados pela ação colonizadora de Fausto e Mefistófeles. A dupla representante da modernidade capitalista não aceita natureza nem história no caminho do progresso. O que irrita o líder do projeto colonizador nas cenas em questão são duas tílias antigas, árvores que por si já representam séculos de história e remontam à mitologia ovidiana, mas que para Fausto não têm função ou valor algum. Além disso, ele se exaspera com o sino da capela de Filemon e Baucis. Em consequência, o casal de anciãos é massacrado junto com um visitante denominado apenas de Peregrino, enquanto árvores e capela são destruídas. Aqui a monografia estabelece uma relação com um episódio em Os sertões:

Nem faltaria, na reconstrução do massacre feita por Euclides da Cunha, um traço que lembra o ódio despertado no colonizador pela sineta de Filemon e Baucis: o destaque que sua narrativa dá ao bombardeio que três canhões Krupp deflagraram sobre "a igreja velha, de madeiramento já todo exposto $[\ldots]$ e em cujo campanário não se compreendia que ainda subisse à tarde o impávido sineiro, tangendo as notas consagradas da Ave-Maria. (p.123) 
"Tens força, tens, pois, o direito", comentaria Mefistófeles (v.11.184). Aprendemos tanto com Goethe como com Euclides da Cunha que ordem e progresso costumam se basear pura e simplesmente na violência. A monografia de Mazzari está cheia dessas observações agudas. Na tragédia goethiana, a destruição das antigas formas "orgânicas" e comunitárias da vida social acontece junto com a destruição da natureza e sua substituição por coisas artificiais no lugar das tílias será erguido um miradouro, como manda Fausto.

Muitos intelectuais da época de Goethe eram anticapitalistas românticos, no sentido que Michael Löwy desenvolveu em Revolta e melancolia (Löwy; Sayre, 2015). A monografia de Mazzari faz alusões aos “dark satanic mills" de William Blake, mas também às advertências ecológicas de cientistas como J. B. Spix e Carl F. P. Martius ou Alexander von Humboldt. ${ }^{1}$ Diferentemente desses e de outros contemporâneos, a produção literária e as pesquisas no campo das ciências naturais sempre andaram juntas em Goethe, para quem a arte e a ciência constituíam uma unidade fundada na natureza. Quase um terço de uma edição impressa da obra goethiana consiste em trabalhos científicos, que até hoje são muitas vezes ignorados pelos Estudos Literários. ${ }^{2} \mathrm{Na}$ sua edição brasileira, Mazzari não abre mão de comentar as diversas cenas do Segundo Fausto que tematizam questões geológicas e meteorológicas. ${ }^{3}$ Durante mais de meio século de pesquisas científicas, Goethe tentou estabelecer um tipo de ciência que entra em contato com a natureza de forma não violenta. No seu pequeno ensaio Recht und Pflicht [Direito e dever] de 1824 podemos ler: "Se o naturalista [der
Naturforscher] fizer questão do seu direito de livre observação e contemplação, ele deve empenhar-se em assegurar os direitos da natureza; vai ser livre somente onde ela estiver livre, onde ela estiver presa aos regulamentos humanos, ele também estará preso".4

A ideia de uma natureza liberta vai ser retomada somente 150 anos mais tarde pelos frankfurtianos Theodor W. Adorno e, principalmente, Herbert Marcuse. Goethe sempre valorizou uma relação não instrumental com a natureza a partir da fenomenologia; para sua mais importante figura literária, Fausto, vale o contrário. Como lidar com um protagonista que fracassa em grande estilo? Lembremos os famosos versos que abrem o monólogo inicial da Primeira Parte da tragédia, nos quais o professor e investigador da natureza declara sua vontade de conhecer o âmago profundo do mundo - esse projeto intelectual acaba no final da Segunda Parte em cegueira completa do protagonista, cegueira literal e metafórica ao mesmo tempo. Seu último gigantesco projeto de colonizar novas terras subtraídas ao mar não cria a base para um povo livre em solo livre, ao contrário: trata-se de uma utopia destrutiva que combina um despotismo irrestrito com a tecnologia que busca domínio total sobre a natureza, como aponta Mazzari. No contexto da discussão do Segundo Fausto dentro da germanística internacional, a leitura proposta na monografia não é nova; o autor mesmo cita importantes precursores e também pesquisadores atuais que mantiveram e mantêm o espírito crítico ao rejeitar leituras identificadoras e/ou perfectibilistas. Mazzari evita também o outro extremo no campo da recepção, o qual nega a relevância atual da obra 
goethiana, como é o caso de Harold Bloom (1995, p. 199), em $O$ cânone ocidental, quando lemos: "Goethe não é mais nosso ancestral [...] Sua sabedoria permanece, mas parece-nos vir de outro sistema solar que não o nosso". Será que, por exemplo, um confronto entre a civilização capitalista moderna e o passado comunitário da humanidade, como acontece nas cenas em torno de Filemon e Baucis, está fora do nosso horizonte atual? Obviamente não. A respeito disso, Mazzari faz uso feliz de um comentário do velho Goethe ao falar em fórmulas ético-estéticas. ${ }^{5}$ Para o poeta alemão, as qualidades estéticas da natureza têm um significado ético, enquanto um filósofo como Adorno ressaltará mais tarde a importância ética das qualidades estético-artísticas. Em seu magistral estudo Eine Ästhetik der Natur [Uma estética da natureza], infelizmente ainda não traduzido para o português, Martin Seel ressaltou que a liberdade estética somente se realiza onde ela indica ao mesmo tempo a liberdade ética. As qualidades estéticas da natureza têm um significado ético; o belo natural faz parte daquilo que atualmente, no contexto latino-americano, chama-se o Bem Viver, concepção que indica uma relação harmônica entre os seres humanos e equilibrada com a natureza. O conceito está ligado a cosmovisões indígenas e ganhou força na primeira década do novo século, quando foi incluído nos discursos oficiais, nas reformas normativas e institucionais na Bolívia e no Equador.

Fausto é tão contemporâneo hoje, em plena era do Antropoceno, como o era no início do século XIX, quando Goethe captou o potencial destrutivo da era industrial que viu manifestar-se in statu nascen$d i$, como comenta Mazzari. Uma figura secundária no Segundo Fausto, Linceu, o Vigia, lamenta a aniquilação da comunidade pré-moderna e a destruição da vegetação nativa com as seguintes palavras: Flâmea língua se esparrama / Pelas hastes, pela rama; / Galhos, crepitando e ardendo, / Ruem em rápida ignição. / Olhos meus, ah! que estais vendo! / Por que tenho tal visão! (v.11324-11329)

Nos últimos anos, temos assistido à destruição da vegetação nativa nas mais diversas regiões do mundo, na Europa mediterrânea, na Califórnia, no Brasil, na Austrália - tudo isso acelerado pela mudança climática antropogênica. "Nascidos para ver, a enxergar destinados", e aparentemente impotentes tal qual Linceu, costumamos receber notícias da destruição ambiental pela internet e pela TV - destruição não do planeta, mas da base de boa parte da vida animal na Terra. Às vezes sabemos "lamuriar" e "gemer" (nas palavras de Fausto) como Linceu e, ainda como ele, acreditamos erroneamente que não podemos interferir. Precisamos de leituras como a de Mazzari para entender a atualidade de um clássico "verde" da literatura mundial.

\section{Notas}

1 Ver, por exemplo, as considerações desenvolvidas no $11^{\circ}$ capítulo (" $\mathrm{O}$ que a vista deliciava, com os séculos se foi’: Uma fórmula ético-estética para a destruição da natureza”), em especial na p.216.

2 A chamada Leopoldina-Ausgabe, edição histórico-crítica e comentada dos trabalhos de Goethe sobre ciências naturais, engloba nada menos do que 29 volumes. Concebida sob os auspícios da Academia Alemã dos Naturalistas (Leopoldina), esta edição pode ser consultada online: 
https://goethe.leopoldina.org/index. html.

3 Vejam-se, por exemplo, os comentários meteorológicos e geológicos no texto introdutório à cena "Alta região montanhosa" (p.749-51); ou ainda, na introdução à cena "Noite de Valpúrgis clássica", as explanações sobre a participação de Goethe na discussão científica de seu tempo em torno da gênese da vida orgânica na Terra, o que levou Charles Darwin a afirmar: There is no doubt that Goethe was an extreme partisan of similar views [isto é, nas fileiras da teoria evolucionista].

4 No original: Wenn der Naturforscher sein Recht einer freien Beschauung und Betrachtung behaupten will, so mache er sich zur Pflicht die Rechte der Natur zu sichern; nur da wo sie frei ist, wird er frei sein, da wo man sie mit Menschensatzungen bindet, wird auch er gefesselt werden.

5 Ver, nesse sentido, os comentários no $5^{\circ}$ capítulo ("Nascido para ver, a enxergar destinado': O vigia Linceu”) sobre a caracterização que Goethe fez de si mesmo, numa carta de 3 de novembro de 1826 , como um "matemático ético-estético" em busca daquelas "últimas fórmulas, mediante as quais o mundo ainda se me torna apreensível e suportável”.

Referências

BLOOM, H. O cânone ocidental. Trad. Marcos Santarrita. Rio de Janeiro: Objetiva, 1995.

ECKERMANN, J. P. Conversações com Goethe nos últimos anos de sua vida: 1823 - 1832. Trad. Mario Luiz Frungillo. São Paulo: Editora Unesp, 2016.

GOETHE, J. W. von. Fausto: uma tragédia - Segunda parte. Trad. Jenny Klabin Segall. 5 ed. rev. e ampl. São Paulo: Editora 34, 2017.

LÖWY, M.; SAYRE, R. Revolta e melancolia. São Paulo: Boitempo, 2015.
MAZZARI, M. V. A dupla noite das tílias. História e natureza no Fausto de Goethe. São Paulo: Editora 34, 2019.

SEEL, M. Eine Ästhetik der Natur. Frankfurt a. M.: Suhrkamp, 1996.
Klaus F. W. Eggensperger é professor de Estudos Literários e Culturais da Graduação e da Pós-Graduação em Letras na Universidade Federal do Paraná, Curitiba, onde fundou o Grupo de Estudos Ecocríticos (Geco). @-klausegge@gmail.com / https://orcid.org/0000-0003-4484-8874

Recebido em 28.1.2020 e aceito em 3.2.2020.

${ }^{\text {I }}$ Faculdade de Letras, Universidade Federal do Paraná, Curitiba, Paraná, Brasil. 